\title{
TRAÇANDO ROTAS E COMUNIDADES \\ DA DIÁSPORA AFRICANA
}

MANNING, Patrick. The African Diaspora: A History Through Culture. Nova York: Columbia University Press, 2009. 394 p.

CURRY, Dawne Y., DUKE, Eric D., e SMITH (orgs.). Marshanda A. Extending the Diaspora: New Histories of Black People. Urbana e Chicago: University of Illinois Press, 2009. 328 p.

HINE, Darlene Clark, KEATON, Tricia Danielle, e SMALL, Stephen. Black Europe and the African Diaspora (orgs.). Urbana e Chicago: University of Illinois Press, 2009. 368 p.

$D_{\mathrm{e}}$ estudos sobre recentes escritores africanos, imigrantes na Itália, a afro- americanos condenados, no século XVIII, na Austrália, os estudos sobre a diáspora africana têm proliferado nas últimas três décadas. Usando numerosos arquivos e abordagens, especialistas de diversas disciplinas revelam a amplitude, a complexidade e a riqueza das histórias dos povos de ascendência africana. Estes estudiosos iluminam as múltiplas migrações, adaptações culturais, movimentos políticos e expressões intelectuais de indivíduos da diáspora africana. Dentro desse crescente corpus de literatura, além disso, muitos têm tentado conceituar, definir e caracterizar a diáspora. Cada vez mais, a diáspora africana tem sido posicionada dentro de contextos sobrepostos, incluindo o Atlântico, o Índico e o Pacífico, bem como o mundo islâmico
Os três livros resenhados contribuem para esta perspectiva, estudando comunidades diaspóricas nas suas mútuas relações e revelando a interconexão dos povos africanos e afrodescendentes através do globo. Fornecem novas ideias sobre a interação entre diferenças e semelhanças em regiões da África, e vão além, destacando as políticas ambivalentes de identidade, cultura e mobilização afro-diaspóricas. Alguns dos autores tentam expandir o entendimento da negritude, especialmente através de seus interesses na Europa negra e nos negros como indivíduos de herança mestiça. Em certos momentos, estes livros também desafiam representações convencionais de quem e o que constitui a diáspora africana e suas culturas. Outros autores, contudo, permanecem confinados a um quadro de referência nacional e privilegiam 
as experiências dos afro-americanos dos Estados Unidos.

As origens do estudo da diáspora africana são frequentemente atribuídas aos historiadores Joseph E. Harris e Shepperson George. Durante uma conferência patrocinada pela UNESCO na Universidade de Dar es Salaam, na Tanzânia, em 1965, estudiosos da história africana se reuniram para discutir a situação desse campo de estudos. Em um painel com Harris, Shepperson apresentou um trabalho no qual introduziu a noção de diáspora nos estudo sobre povos africanos e afro-descendentes. ${ }^{1}$ Shepperson procurou alargar a historiografia africana e contestou a análise "pan-africanista" anterior, enfatizando as articulações temporais, espaciais e transnacionais. Ressaltou que uma série de eventos culturais, políticos e históricos, desde o movimento pelos direitos civis nos EUA aos movimentos anticoloniais na África e em outros lugares, ajudaram a informar os estudos sobre a diáspora africana. Por fim, demonstrou a utilidade de cruzar as fronteiras, a fim de examinar a diversidade de culturas africanas no âmbito transnacional.

Seguindo esta tradição, The African Diaspora, de Patrick

George Shepperson, "The African Abroad or the African Diaspora," in Terence O. Ranger (org.), Emerging Themes of African History (Nairobi: East African Publishing House, 1968), pp. 152-76.
Manning, é uma história cultural sintética da diáspora africana de 1400 ao ano 2000. Escrevendo para o grande público, Manning incentiva uma abordagem mais "interativa" ou "conectiva" para estudos da diáspora que explore a história em larga escala. Com base em seus interesses anteriores na escravidão e no tráfico de escravos, Manning entrelaça estudos da África pré-colonial com os de sociedades após a abolição. Enfoca o papel que a África e a sua diáspora têm desempenhado na história mundial, penetrando em um mundo moderno e contribuindo para diversas sociedades. O estudo das experiências africanas e afro-diaspórica em todo o mundo, segundo ele, é fundamental "para a compreensão das realizações e erros que continuam a moldar a modernidade" (p. xvii). Inspirado no modelo do Atlântico Negro de Paul Gilroy, Manning trata o oceano como uma ponte que permitiu aos africanos e seus descendentes criar comunidades viáveis, redes e intercâmbios ao longo dos séculos. Aqui, ele tenta dar às diásporas a mesma atenção que as nações e o nacionalismo frequentemente recebem.

Em cada um dos sete capítulos do livro, traça as transformações sociais, culturais e econômicas, devidas à migração africana no continente, além de escavar a vida cotidiana de pessoas. Cinco temas emergem ao longo do livro: "a diáspora e suas conexões, 
o discurso sobre raça, transformações econômicas, vida familiar e produção cultural" (p. 2). Manning situa seu estudo em três regiões: "a terra natal do Africano" (África Subsaariana); “a diáspora no Velho Mundo" (África do Norte, o oeste, sul e sudoeste da Ásia, Europa e as ilhas do Oceano Índico); e "a diáspora no Atlântico" (Américas, ilhas atlânticas e Europa Ocidental) (pp. 3-4).

Criticando a noção de "afrocentricidade" de Molefi Asante, a ênfase de Paul Gilroy em "Atlântico Negro", e aspectos da abordagem de John Thornton, Manning afirma que o primeiro desconsidera os temas da escravidão e da emancipação na África, bem como no exterior, como a Europa, América Latina e o Oceano Índico. Embora acolha o objetivo de Asante de cultivar o orgulho na comunidade afro-americana, Maning sustenta que este autor não considera a mudança ao longo do tempo na África e sua diáspora, e não reconhece a diversidade das comunidades na África. Argumenta que Gilroy confundiu diáspora africana com Atlântico Negro, deixando de abordar as suas diferenças. Acrescenta que, embora Gilroy tivesse analisado a construção da negritude e o surgimento de uma "contracultura da modernidade" negra, ele negligenciou a integração dos estudos sobre a África antes e depois da emancipação. Por último, critica o foco de Thornton nas elites africanas em vez das classes populares. Manning afirma que, em contraste com essas interpretações, a sua "abordagem conectiva" centraliza a África e a sua diáspora na história global e ilumina as interações e redes comunitárias que evoluíram entre as elites e o povo em toda a África e alhures. Evitando caracterizações limitadas do continente e de seu passado, também revela como - e aqui recorro a Raymond Williams "culturas emergentes" e "residuais" concebem o continente e sua diáspora desde antes do contato europeu e após a emancipação. Assim, por exemplo, a discussão sobre o mbira que se desenvolveu no Zimbabwe pode informar nossa compreensão do crescimento do son afro-cubano e da rumba em Cuba.

Nos dois primeiros capítulos, Manning trata da migração dentro da África e das crônicas individuais, muitas vezes de escravos, que viajavam da região subsaariana para o norte de África, Oceano Índico, Ásia, Oriente Médio e Europa. Ele explica que asiáticos e europeus estabeleceram-se na África, dando exemplos de negócios multidirecionais, e defende e detalha que ideias, culturas, práticas religiosas, culturais e instrumentos musicais espalharam-se para várias regiões bem antes da expansão europeia. Por volta de 1600, o papel da África na expansão europeia se transformou quando começou a for- 
necer mais mão-de-obra escrava. Manning aborda o tráfico, as múltiplas formas de escravidão e "lutas pela sobrevivência" no continente e em toda a diáspora, de 1600 a1800.

Manning ressalta que, embora a travessia atlântica fosse brutal e desumana, os cativos não eram impotentes, em parte porque mantinham fortes ligações com suas tradições culturais, espiritualidade, valores sociais e estruturas familiares. Ele analisa como a expansão da escravização, do fim do século XVIII até 1860 , ocorreu simultaneamente às campanhas contra o tráfico de e a escravidão. Com a relutância dos defensores da escravidão em ceder, uma forma mais insidiosa de racismo emergiu. Esta noção renovada de racismo (científico) seria uma resposta ao movimento abolicionista para justificar a opressão de pessoas de cor livres no pós-emancipação. Esses processos de racialização informaram projetos de construção nacional que Manning ilustra como a ascensão do apartheid nos EUA na década de 1880 e 1890, paralelamente à segregação na África após a partilha colonial.

Tratando do século XX, ele se concentra mais minuciosamente no mundo Atlântico. Do avanço dos direitos civis nos EUA, os movimentos de independência no Caribe e na África, a reivindicações na América Latina, Manning caracteriza os anos 1900-1960 como de intensa "luta pela cidadania". O período também testemunhou profundas invenções culturais e vitórias notáveis alcançadas pelos povos da diáspora. Em seguida, define o período de 1960 a 2000 como de "luta pela igualdade", durante o qual os povos africanos e afrodescendentes obtiveram avanços significativos na educação, no poder político e mobilidade social. No epílogo, Manning reflete sobre o crescimento da escravidão no mundo moderno e as contribuições das comunidades afro-diaspóricas em todo o globo. Ele conclui que, apenas considerando a inter-relação passado/presente que os povos africanos e afrodescendentes partilharam e partilham, os estudiosos e o grande público podem começar a compreender a dinâmica da história humana.

A tentativa de Manning de vincular a diáspora africana à história mundial deve ser aplaudida. No entanto, ao estabelecer paralelos, conexões e comparações, ele às vezes minimiza as diferenças, rupturas e descontinuidades na diáspora. Em muitos casos, a solidariedade intra-diaspórica foi repleta de tensões. Para várias comunidades, a heterogeneidade, e não as semelhanças, desempenhou um papel fundamental para moldar identidades diaspóricas. Quanto ao século XX, Manning poderia ter melhor discutido vários movimentos diaspóricos que deliberadamente ampliaram fronteiras nacionais para ajudar a moldar 
suas identidades e práticas locais. Acompanhar o movimento Black Soul no Brasil e o ativismo Hip Hop na Europa, por exemplo, poderia ter aperfeiçoado sua análise. Com a ênfase na travessia atlântica e no afroAtlântico, especialmente na América do Norte, ele parece favorecer determinados caminhos e posições que giram em torno da escravidão, sobrevivência, abolição e resistência, relegando outros membros da diáspora às margens. Por exemplo, os imigrantes da nova diáspora africana dos séculos XX e XXI não se encaixam perfeitamente nessa trajetória. É necessário que todas as comunidades da diáspora sigam aquele caminho, para ganhar atenção dos estudiosos? Há espaço para estudos críticos que não se detenham na travessia ou numa perspectiva afro-atlântica?

Os organizadores de Extending the Diaspora acreditam ser imperativo atravessar as fronteiras nacionais e geográficas, a fim de desenvolver uma compreensão mais rica da diversidade de culturas, comunidades e experiências que constituem a diáspora africana. Assim, os ensaios neste livro entrelaçam análises de localidades geográficas aparentemente não relacionadas para propor "uma meta-narrativa sobre raça, política, sexo e nacionalidade, entre outros assuntos relacionados" (p. xiv). O livro é dividido em quatro partes. A primeira apresenta relatos das lutas de indivíduos escravizados por liberdade na Jamaica, Brasil e Canadá. Usando registros notariais, John F. Campbell contesta visões predominantes sobre o Caribe britânico, antes de 1834 , que frequentemente enfatizam que a alforria era ali uma prática disseminada. Focalizando a Jamaica, ele argumenta que a alforria não ameaçou diretamente o sistema escravista, mas serviu aos interesses dos brancos, como um instrumento de controle social. O capítulo de Beatriz Mamigonian explora outro exemplo de liberdade precária, no caso africanos resgatados de navios negreiros no Brasil após a proibição do tráfico em 1831. Os chamados "africanos livres " permaneceram sob a "tutela" do governo imperial brasileiro, por décadas, como trabalhadores forçados em instituições públicas, enfrentando jornadas muito mais duras e fatigosas do que aqueles que trabalhavam para particulares. Por último, situando o Canadá dentro das narrativas da diáspora africana, Afua Cooper fornece o esboço biográfico de um escrava rebelde, Marie-Joseph Angélique, "negra portuguesa" executada por ter, supostamente, provocado o incêndio de Montreal em 1734. Cooper traça as rotas de Angélique de Portugal à Nova Inglaterra e, em seguida, a Montreal, e atribui sua resistência à escravidão no Canadá a um desejo de liberdade e de retorno a sua terra natal, Portugal. 
Na segunda parte, os autores destacam os intercâmbios de afro-americanos com os haitianos, afro-brasileiros e sul-africanos. Stephen Hall interpreta como escritores afro-americanos do século XIX usaram a Revolução Haitiana como poderosos "emblema e símbolo" (p. 77) na luta antiescravista. Hall revela que esses intelectuais fizeram uso de diversas estratégias históricas e retóricas para esculpir espaços próprios e legitimar suas causas, apresentando a história revolucionária do Haiti como um exemplo positivo do que os EUA podiam aspirar a se tornar. Micol Seigel contextualiza as conexões diaspóricas entre o editor do Chicago Defender, Robert Abbott, e os leitores e colaboradores de jornais afro-brasileiros em São Paulo na década de 1920. Afastando-se da presunção de que "pessoas de ascendência africana dos Estados Unidos preferem o confronto racial consciente e coletivo, e no Brasil a assimilação individualista nacionalista" (p. 100), ela argumenta que os afro-brasileiros eram confrontadores e racialmente conscientes. Seigel explica que os afro-brasileiros eram críticos à crença dos afro-americanos de que o Brasil fosse um "paraíso racial" e se opuseram à sua imigração para o País. No entanto, mesmo com essas tensões e críticas, essas comunidades se assemelhavam em em perceber suas escolhas como políticas, anti-racistas e nacionais. Iris Berger encerra a seção examinando o legado político de Madie Hall Xuma, uma mulher afroamericana que se casou com A. B. Xuma, médico e então presidente-geral do Congresso Nacional Africano, na África do Sul. Durante seus vinte e três anos nesse país (1940-1963), ela se tornou uma ativista importante nos clubes Zenzele - organizações de autoajuda de mulheres. Berger mostra como conceitos elitistas de progresso e melhoria racial reforçavam o compromisso de Xuma em inculcar padrões morais, consciência política e habilidades domésticas entre as mulheres sul-africanas.

Indo além do mundo atlântico, a terceira parte inclui artigos sobre a diáspora africana na Austrália e no Japão. Cassandra Pybus ilumina as "micro narrativas" de onze condenados que criaram uma comunidade em New South Wales, Austrália, em 1788. Mapeando as migrações a partir de Nova Escócia, Jamaica, Bahamas, Inglaterra, e depois Sydney Cove, ela recupera as experiências de homens de ascendência africana que desempenharam um papel fundamental na formação do império britânico. Por último, Yuichiro Onishi examina grupos pacifistas de soldados afro-americanos e brancos, japoneses e civis americanos, bem como a população local, no movimento de libertação de Okinawa durante a ocupação da ilha pelos EUA de 1968 a 
1972. Ele ilustra como a organização das bases populares em Okinawa se apropriou do radicalismo negro, da ideologia de libertação do Terceiro Mundo e de outras tradições intelectuais, e, assim, demonstra que "a panmobilização de não-brancos" no Japão não foi exclusivamente baseada em políticas identitárias (pp. 180182). Okinawa permaneceu um espaço repleto de tensões raciais, até mesmo quando seus habitantes, ativistas pela paz e soldados americanos (brancos e negros) conduziam campanhas multifacetadas contra o "branqueamento global", o anti-imperialismo e o militarismo.

Voltando ao mundo atlântico, a última seção traça os significados inconstantes de raça e nação na Inglaterra, no Sudoeste da África, Haiti e na África do Sul. Joel T. Helfrich sustenta que lutas de boxe, no século XIX, entre um inglês branco, Tom Cribb, e um afro-americano, Tom Molineaux, "ajudaram a consolidar e solidificar uma identidade nacional britânica" (p. 206). Defende que as representações dos pugilistas em jornais e no discurso público sancionaram noções de raça, masculinidade, política internacional e ideologia nacionalista. Em seguida, Fátima ElTayeb argumenta que a colonização alemã no sudoeste da África desempenhou seu papel na racialização de uma identidade nacional germânica. Ela analisa como a lei antimiscige- nação, de 1905, nas colônias, serviu para definir como brancas as fronteiras da germanidade excluiu os filhos de descendência afro-alemã dos direitos de cidadania. ,. Essas práticas discriminatórias, além disso, estabeleceram um precedente para o tratamento das minorias alemãs supostamente inferiores racialmente. Matthew Smith explora como movimentos marxistas no Haiti, do fim da ocupação americana, em 1934, até a era Duvalier, em 1957, "mostraram uma alternativa política que foi além tanto do marxismo tradicional como do noirisme mais popular em sua heterodoxia" (p. 246) . Finalmente, Dawne Curry termina a coletânea examinando a construção social de identidade, raça, nacionalidade e gênero, com base em suas experiências na África do Sul. Utilizando uma abordagem etnográfica, ela enfatiza que a identidade está ligada não só à experiência vivida, mas também a práticas sociais, cultura e linguagem.

Tomados em conjunto, os ensaios reunidos em Extending the Diaspora mostram como a construção de significados de raça e gênero conformaram ideologias e foram fundamentais para projetos de construção nacionais em todo o globo. Não obstante o rigor intelectual e sua abrangência geográfica, , o livro poderia ser mais equilibrado em sua cobertura. Embora os organizadores reconheçam a necessidade de ir além das fronteiras 
nacionais e geográficas, tendem a privilegiar as experiências afro-americanas, examinando suas interações em diversos locais do globo. Embora essas narrativas sejam significativas, não devem ser tomadas como único modelo da diáspora.

Black Europe and the African Diaspora analisa a complexidade da Europa negra. Os autores "teorizam", "representam" e "reimaginam" essa Europa, reconhecendo como ela foi construída através do tempo e do espaço. A força do livro reside na sua capacidade de usar uma variedade de abordagens disciplinares, embora sua prosa, muitas vezes densa, limite o seu valor como uma introdução geral à ao tema. $\mathrm{O}$ livro inclui um prefácio escrito por Filomena Essed. Sensível tanto aos pontos fortes e às limitações do conceito de Europa negra em estudos acadêmicos, e às hierarquias existentes entre as populações da diáspora, Essed incentiva os leitores a usarem a coletânea para estudos analíticos e empíricos adicionais sobre o assunto.

O sociólogo Stephen Small analisa a evolução do estudos sobre a Europa negra, começando com a publicação do texto canônico, de 1982, The Empire Strikes Back, do Centro de Estudos de Cultura Contemporânea. Small também introduz questões metodológicas, prioridades e conceitos, apresentando uma discussão sobre classe, desigualdade social, Es- tado, ideologias de gênero e experiências de mulheres negras em toda a Europa. Ele reconhece a importância da pesquisa sobre diáspora africana nos EUA, mas se preocupa que "conceitos de outros lugares impeçam o surgimento de conceitos apropriados, localmente específicos, em desenvolvimento na Europa" (p. xxx).Small insiste que futuros estudiosos devem compreender e contextualizar termos dentro de suas circunstâncias locais, nacionais e regionais.

Os capítulos de Allison Blakely, Dienke Hondius, Stephen Small e Kwame Nimako contextualizam a diáspora africana, traçando as mudanças históricas, demográficas e políticas que moldaram a presença negra em toda a Europa.Fornecendo uma visão geral da transição de africanosna-Europa para afro-europeus, Blakely afirma que as preocupações e debates recentes sobre a imigração negra africana esquecem a presença histórica dos africanos e afrodescendentes na Europa. Interpretando a migração de trabalhadores afro-europeus, Small e Nimako investigam como a negritude na Grã-Bretanha tem sido articulada em debates recentes sobre $o$ advento de imigrantes africanos para a Europa. Eles revelam que as noções de comunidade negra e de diáspora africana mudaram na Europa desde os anos 1960 e 1970, refletindo a chegada de pessoas da África pós-colonial. O sentimento 
nativista em toda a Europa continental continua a marginalizar e excluir os afro-europeus, atribuindo-lhes muito pouco prestígio, particularmente dentro da União Europeia. Por último, Hondius examina a chegada de 130 "mouros" em Middleburg, na Holanda, em novembro de 1596 -os primeiros africanos a chegar ali -antes de voltar às recentes discussões sobre a diáspora africana. Os holandeses, segundo ela, estão começando a assumir a responsabilidade por seu passado colonial. Hondius ilustra como uma anterior amnésia coletiva sobre 1596 ajudou a manter "as realidades visíveis do tráfico de escravos longe da Holanda" (p. 39).

As contribuições de Fred Constant, Terri Francis, Eileen Julien, Tricia Danielle Keaton, T. SharpleyWhiting, Tiffany Rubi Patterson e Tyler Stovall chamam atenção para a interação de populações racializadas, pertencimento, identidade e diferença na França. Sharpley-Whiting e Patterson estudam como a missão civilizadora da França em suas colônias ultramarinas permaneceu uma iniciativa de assimilação que abominava a diferença cultural. Nessa perspectiva, todos tinham que se tornar franceses, embora a França não tivesse estendido a cidadania a todas as suas populações coloniais na Martinica, Guadalupe, Guiana Francesa e Reunião até 1946. No caso francês, as fronteiras geográficas do europeísmo negro se estenderiam além da Europa continental. Usando filmes estrelados por Josephine Baker, particularmente "Zou Zou" (1934) e "Princesse Tam Tam" (1935), Julien analisa a ansiedade francesa com a tolerância a pessoas de cor no país, apesar da declarada missão civilizatória da França. Esses filmes, ela argumenta, permitiram a Baker alcançar projeção e serviram "como veículos de exploração francesa da identidade racial e do pertencimento nacional" (p. 48). Continuando a focar experiências afro-americanas, Keaton examina a imigração na França com vistas a desestabilizar "narrativas de inclusão de imigrantes negros “ (p. 96). Relatos recentes de negros americanos expatriados, segundo ela, perpetuaram mitos de longa data de que na França não há discriminação racial.Neste caso, ela reconhece que as experiências dos negros americanos na França têm sido diferentes das de minorias raciais locais. Usando as rebeliões de Paris, em 2005, e narrativas contemporâneas de negros americanos, Keaton sustenta que o daltonismo francês só existe em teoria. Da mesma forma, discutindo os recentes acontecimentos raciais na França, Constant argumenta que as atitudes raciais ali são baseados em uma combinação de estereótipos culturais e biológicos. O discurso oficial daltônico resulta em atitudes contraditórias que envolvem 
tanto a tolerância ao multiculturalismo quanto a manutenção de uma ordem de exclusão social. Comparando a exclusão social e os discursos raciais, Stovall afirma que a experiência afro-americana na França já começou a espelhar a vida afro-americana nos EUA, desestabilizando o alegórico daltonismo francês, especialmente para os afro-americanos. Por último, diferindo em ênfase dos demais artigos sobre a França, Francis explora como Josephine Baker "serviu como uma apologia ao potencial cultural negro", e como "o seu sucesso na França forneceu contra-exemplos para as restrições à vida negra, especialmente o sucesso negro, nos Estados Unidos “ (p. 243). Focalizando as representações e as danças 'primitivas' dos filmes de Baker, ela afirma que a atriz representava uma imagem de modernização e transnacionalidade que refletia sua complexidade, criatividade e protagonismo.

Os próximos capítulos avaliam culturas visuais, musicais e literárias na Alemanha e Itália. O artigo de Tina Campt interpreta as fotografias de família de Hans Hauck, um afro-alemão nascido em 1920 de mãe branca alemã e pai argelino. Campt mostra que as fotografias presumivelmente comuns servem como "um lugar complexo que retrata e reflete a política de formação diaspórica negra europeia" (p. 65), permitindo-lhe explorar "a "indexicalidade da raça" e analisar a constru- ção visual de classe, raça, gênero, diáspora e pertencimento durante determinados momentos da história alemã. Voltando-se para grupos de Hip Hop e Rhythm \& Blues afro-alemães, tais como "Brothers Keepers" e "Sisters Keepers", Alexander G. Weheliye analisa de que modo a música funciona como uma ferramenta diaspórica para comunidade, pertencimento, identidade e peoplehood na Alemanha. Para Weheliye, os afroalemães não podem ser tratados como ein Volk, visto que são negros e alemães. Ecoando teses de Gloria Anzaldúa, Homi Bhabha e Karein Goertz, Weheliye argumenta que a subjetividade afro-alemã funciona como um espaço liminar permitindo uma compreensão da cultura que evita a ideia simplista de nações "puras" ou comunidades naturais. Alessandra Di Maio salienta que, na Itália, uma comunidade do Chifre da África tem produzido uma nova literatura imigrante e que as africanas, em particular, têm utilizado a literatura como uma forma de diálogo dentro da sociedade italiana. Ela afirma que a "pluralidade constitui o princípio da organização textual" (p. 132) da literatura italiana imigrante contemporânea.

Usando seu grupo familiar como ponto de partida, Jacqueline Nassy Brown define identidades individuais e coletivas na diáspora, numa tentativa de compreender o papel do de- 
sejo na diáspora. Com esta ênfase, Brown explora os "encontros situados no qual as pessoas realmente expressam algum tipo de desejo de conexão" (p. 201). A diáspora, Brown explicita, não se baseia unicamente no deslocamento, mas deve ser vista como relacional, em que parentesco, pertencimento e circunstância conformam as interações que ocorrem entre indivíduos da diáspora africana.

Os dois últimos artigos, de Michelle M. Wright e Gloria Wekker, expõem as limitações dos conceitos de negritude e Europa negra. Esboçando conexões entre brancos e o humanismo liberal negro, Wright destaca questões epistemológicas nas definições de negritude que reclamam inclusão, mas persistentemente excluem mulheres e gays. Ela descentraliza perspectivas masculinistas heteronormativas e narrativas sobre a travessia atlântica que "lutam para realmente incorporar 'outras' [...] identidades negras, levando teóricos tais como Shelby e Gilroy a, paradoxalmente, clamar pelo silenciamento / apagamento da diferença a fim de estabelecer a diversidade"(p. 265). Aqui, Wright procura diversificar as epistemologias usando a Segunda Guerra Mundial "como um tropo formativo" (p. 272) das identidades negras na Europa. Em seguida, Wekker interroga o conceito de Europa negra e revela que a sua construção, como conceito acadêmico, ocorreu princi- palmente fora da Europa. Ela explica as dinâmicas geopolítica e de poder que existem dentro Europa negra, as tensões na Europa e "as formas que a 'europeização racial' ... tomam no contexto holandês "(p. 278). Partilhando as ideias de Wright sobre a figura da travessia atlântica, Wekker demonstra que há hierarquias e noções concorrentes de negritude em vigor no interior da diáspora que privilegiam algumas narrativas em detrimento de outras. Finalmente, o breve posfácio de Barnor Hesse encerra o volume com um comentário adicional sobre Europa negra.

Black Europe and the African Diaspora oferece análises desafiadoras sobre quão importantes foram os indivíduos africanos e afro-descendentes para a constituição da sociedade europeia. No entanto, embora os artigos sobre a França sejam excelentes, sua ênfase no mito do daltonismo francês poderia ter sido complementada por exemplos de ativismo e identidade afro-franceses. Não obstante a introdução de Small, alguns dos autores, por vezes, combinam os rótulos negro e africano de maneira particularmente problemática, o que torna difícil distinguir entre os dois conceitos em contextos europeus. Por exemplo, nos Países Baixos e na Grã-Bretanha, nem todo mundo que é "africano" é "negro", e nem todo mundo que é "negro" é "africano". Finalmente, incentivando 
os pesquisadores a se estenderem além das fronteiras nacionais e geográficas, o livro é ambivalente em seu tratamento do Estado-nação. Podem estudos da diáspora transcender a nação sem reafirmá-la? E os estudos confinados aos Estados-nação são inerentemente ruins?

Para concluir, esses livros destacam vários temas que estão a orientar a pesquisa atual sobre estudos da diáspora africana. Primeiro, alguns dos autores enfatizam a simultaneidade da diferença e da semelhança na diáspora-ideias expressas anteriormente por Audre Lorde, Stuart Hall e Thomas Holt. ${ }^{2}$ Enquanto Manning observou comparações e ligações na África e através da diáspora, Campt, Weheliye, Brown, Wekker, Wright e Seigel analisaram as diferenças e as tensões que existem no interior da diáspora. Esses estudiosos mostraram como os sujeitos alteram, afirmam e reimaginam suas conexões diaspóricas de forma complexa ao longo do tempo e do

Aurde Lorde, Sister Outsider: Essays and Speeches, Berkeley: Crossing Press, 2007 [1984]; Stuart Hall, "Cultural Identity and Diaspora", in Jonathan Rutherford (org.), Identity: Community, Culture, Difference (Londres: Lawrence and Wishart, 1990), pp. 222-37; Thomas Holt, "Slavery and Freedom in the Atlantic World: Reflection on the Diasporan Framework", in Darlene Clark Hine e Jacqueline McLeod (orgs.), Crossing Boundaries: Comparative Histories of Black People in Diaspora (Bloomington: Indiana University, 1999), pp. 33-44.
espaço.Os ensaios ressoam obras recentes de Lena Sawyer e Jayne O. Ifekwunigwe, que reconhecem a importância da heterogeneidade, atentando para as formas específicas que a ideia de raça tem sido implantada em várias comunidades diaspóricas, examinando "novas diásporas africanas 'transnacionais / extracoloniais", e situando experiências de gênero e sexo na diáspora africana. ${ }^{3}$ Ao fazer isso, eles exploram como a diáspora africana funciona dentro e fora de fronteiras. Também é importante notar que esses estudos exploram a natureza complexa da diáspora, focalizando as abordagens geracionais, de classe, gênero, étnicas, locais, nacionais para formação de identidades e noções de pertencimento. No entanto, poderiam às vezes melhor enfatizar a diferença entre a diáspora africana em si e como as pessoas afirmam, imaginam, promulgam e usam a diáspora como um meio de forjar conexões e relacionamentos.

Em segundo lugar, alguns dos

Ver Lena Sawyer, "Engendering 'Race' in Calls for Diasporic Community in Sweden", Feminist Review, n. 90 (2008), pp. 87-105; Jayne O. Ifekwunigwe, "Black Folk Here and There': Repositioning Other(ed) African Diaspora(s) in/and 'Europe", in Tejumola Olaniyan and James H. Sweet (eds.), The African Diaspora and The Disciplines ( Bloomington: Indiana University Press, 2010), pp. 313-38; citação da p. 313; e Diaspora and the Localities of Race, v. 27, n. 1 (2009), especialmente os artigos de Minkah Makalani, Tina Campt, Jacqueline Nassy Brown e Frank Guridy. 
autores expressam as suas preocupações sobre um modelo afro-atlântico, que privilegia a travessia atlântica. Os livros tentam transcender fronteiras geográficas e nacionais, enquanto mostram contextos globais e transnacionais da diáspora. No entanto, alguns dos autores têm uma tendência a excluir outros membros na diáspora africana, na medida em que às vezes dão a entender que os indivíduos seguem padrões e trajetórias semelhantes diáspora afora. Diferindo desta abordagem estão os trabalhos de Ifekwunigwe, Pier Larson e Paul Tiyambe Zeleza, que propõem perspectivas sobre a evolução de diversas populações afro-diaspóricas. ${ }^{4} \mathrm{Se}$ gundo suas agendas de pesquisa, esses estudiosos, como nos segundo e terceiro capítulos de Manning, mostram como os padrões atlânticos de imigração, religião, demografia, estrutura familiar e consciência racial não foram os mesmos presentes em outras diásporas. Por fim, autores como Zeleza e Ifekwunigwe também reconhecem que novas diásporas africanas têm surgido em todo o mundo, descentrando o paradigma da travessia atlântica e descobrindo outros padrões de comunidade e mobilização diaspóricas. Mas no final, cruzando fronteiras e contextualizando as experiências vividas dos indivíduos da diáspora africana, os livros aqui discutidos ilustram como essas comunidades têm existido faz longo tempo, em diversas localidades, devido a condições históricas específicas.

Tiffany Florvil Universidade da Carolina do Sul Tradução de Mariângela Nogueira

\footnotetext{
4 Pier M. Larson, "African Diasporas and the Atlantic," in Jorge Canizares-Esguerra e Erik R. Seeman (orgs.), The Atlantic in Global History, 1500-2000 (Upper Saddle River: Prentice Hall, 2006), pp. 129-47; e Paul Tiyambe Zeleza, "Rewriting the African Diaspora, Beyond the Black Atlantic", African Affairs, v. 104, n. 414 (2005), pp. 35-68.
} 